\title{
Green Biopolymers for Ecofriendly Leather
}

\author{
Valentina Beghetto ${ }^{1}$, Fabrizio Ugolini ${ }^{2}$, Alessandra Tortora ${ }^{2}$, Lorenzo Taddei ${ }^{2}$, Alberto Scrivanti ${ }^{1}$ and Roberto \\ Sole ${ }^{1}$ \\ 1. Dipartimento di Scienze Molecolari e Nanosistemi, University Ca'Foscari Venezia, Via Torino 155, Venezia Mestre 30172, Italy \\ 2. Codyeco S.p.a., Via del Grano 8, S. Croce sull'Arno, Pisa 56029, Italy
}

\begin{abstract}
Green and eco-friendly reagents for the leather industry based on Biopolymers (Biopol) have been developed through Life Biopol European project. The new biopolymers represent an innovative, non-hazardous and environmentally sustainable alternative to traditional products based on petrochemicals. Biopol are a virtuous example of circular economy since they are obtained from industrial by-products such as animal and vegetable biomasses otherwise disposed in landfill. Several protocols are under investigation in order to produce chemicals to replace the traditional ones. NMR, FT-IR characterization of the Biopol will be carried out in order to rationalize the synthetic strategy and practical application of the products giving important parameters such as molecular weight and chemical composition of the new biopolymers. Preliminary performances of new synthesized biopolymers have been inspected and compared with traditional chemicals through the leather making process.
\end{abstract}

Key words: Green tanning agents, leather industry, biopolymers, biomass recycle, waste recovery.

\section{Introduction}

Leather processing is one of the earliest industrial activities taken up by mankind. Today the leather industry significantly contributes to economic welfare, and is facing global environmental challenges in order to reduce pollution level and chemical hazard [1-3]. According to data recently updated by the European Commission [4], the leather industry and related goods sector comprise about 36,000 enterprises and generate a turnover of 48 billion euro/year with around 435,000 employees. According to 2013 Euro-leather's report [5], the European leather industry production is responsible for $19 \%$ of the worldwide leather market. In 2015 Italy has covered $65 \%$ of the European production, corresponding to an annual turnover of 5.0 billion euro/year and a production of 127 million $\mathrm{m}^{2}$ of finished leather. The leather industry processes animal skin or hide, which by tanning is transformed into a durable material preventing its decay [6]. Nevertheless, leather making is highly environmental demanding [7] and according

Corresponding author: Valentina Beghetto, Ph.D., research fields: industrial organic chemistry, green manufacturing. to European Directive 96/61EC, it is considered to be an activity requiring integrated prevention and control of pollution since huge amount of solid and liquid wastes are formed giving rise to pollution that needs to be overcome by introducing sustainable cleaner technologies [8]. In order to protect environment and laborers, EU has compiled BREF (best available techniques reference document) and IPPC UE 2008 Directive [9], highly recommending the reduction of water consumption in the leather making process and pushing to the identification of efficient and sustainable alternatives concerning the use of Non-Hazardous Substances and more environmentally friendly products, which can also guaranty a reduction in the Carbon Foot Print. Moreover, LCT (life cycle thinking) seeks to improve goods and services environmental impact and reduce the use of resources across all life cycle stages in agreement with circular economy principles [10]. This virtuous cycle starts from raw material extraction to waste management [11]. Reduce, reuse, recycle and recover of the tannery effluents are principles which are leading the industry ways of managing tannery wastes.

In this paper we wish to report Life Biopol 
preliminary investigations regarding recycle and reuse of animal biomass waste, as secondary starting material for the production of tanning, retanning or fattening agents. In particular, HC (hydrolyzed collagen), a natural biodegradable polymer easily available at low cost, can be converted by polymerization, esterification and sulphitation into modified poly amino acids or Biopols (Scheme 1). The use of biopolymers for economic and environmentally sustainable development is currently growing. The HC is obtained from fleshing and shaving of the hide produced during the tannery process and is mainly constituted of raw collagen [12].

This approach is highly environmental since: (i) no metal formaldehyde or phenol containing agents are employed; (ii) waste biomass is recovered to produce high value chemicals for the leather industry; (iii) reduction of chrome containing solid and liquid waste.

\section{Materials and Methods}

All the reagents were purchased from Sigma Aldrich and used without any purification. HC was purchased from ILSA S.p.a. and leather from CODYECO S.p.a.

All NMR spectra were acquired in deuterium oxide $\left(\mathrm{D}_{2} \mathrm{O}\right)$ and recorded by using a spectrometer Bruker
Avance 300 working at a frequency of $300.13 \mathrm{MHz}$ for the proton spectrum in deuterium oxide as deuterated solvent.

FT-IR spectra were recorded by using a spectrometer Perkin-Elmer Spectrum One, in a range frequency 4,000 a $400 \mathrm{~cm}^{-1}$. All the samples have been prepared in $\mathrm{KBr}$.

Mini-PROTEANÆ Tris-Tricine precast gels and Polypeptide standards (Bio-Rad) were used for SDS-PAGE analysis.

\section{Experimental}

3.1 General Procedure for Intermediate Synthesis (Biopol A)

A glass reactor fitted with stirrer, heating mantle and condenser has been used for the synthesis of biopolymers. The reaction was carried out at variable temperatures between $50{ }^{\circ} \mathrm{C}$ and $100{ }^{\circ} \mathrm{C}$.

Initially a polyol is heated into the reactor and animal biomass is added. Once a homogeneous dispersion is achieved, the condensation agent is added. The temperature is raised from room temperature to $100{ }^{\circ} \mathrm{C}$ in 30 minutes and the reaction is allowed to continue for several hours till the desired molecular weight is achieved. The synthesized

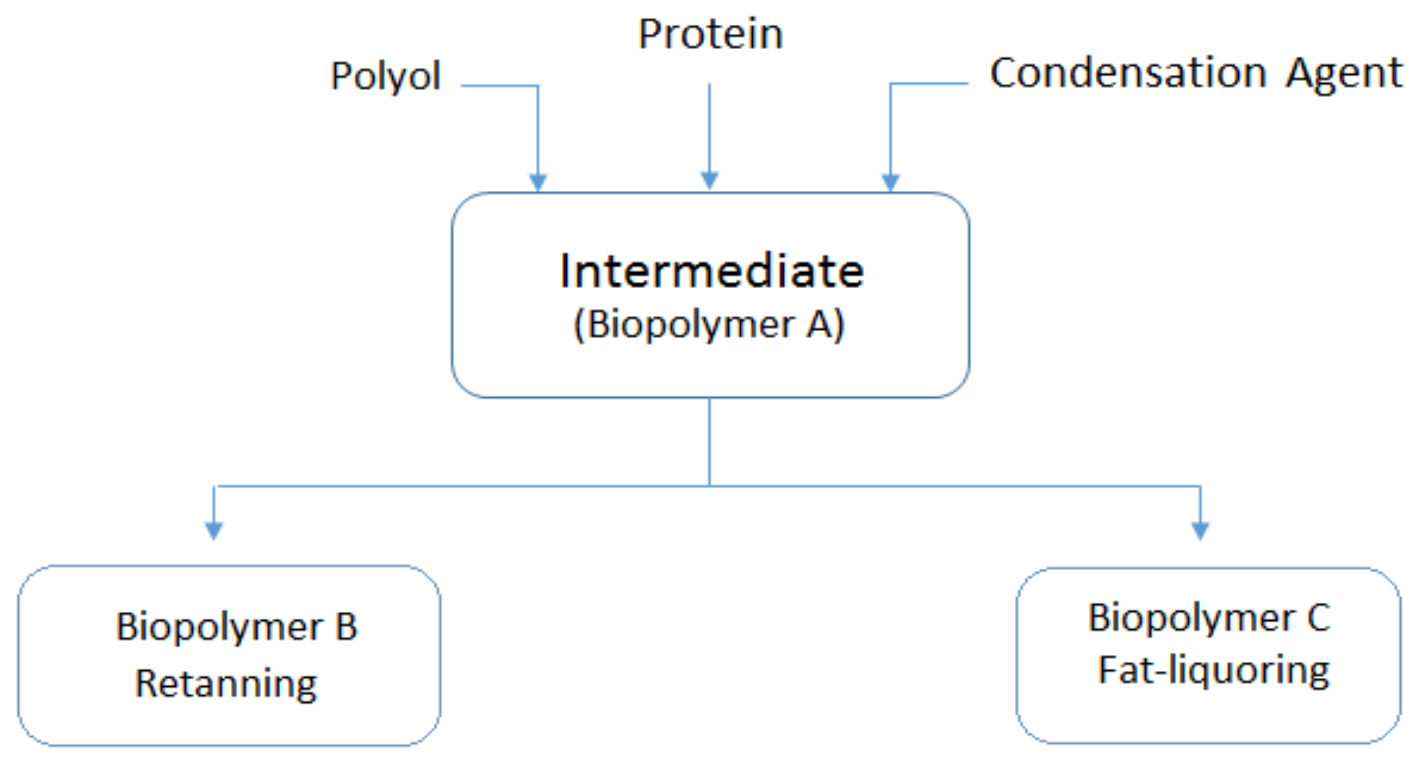

Scheme. 1 Synthesized biopolymers used in different leather making steps. 
intermediate can be used as it is or as intermediate to produce a range of biopolymers for different leather making steps, as mentioned in Scheme 1 and described below.

\section{Results and Discussion}

Presently over $85 \%$ of the hides processed worldwide is tanned in the presence of chrome salts which allow to produce high quality leather goods at low prices. In fact, chrome salts are cheap, easy to use, versatile, etc. Nevertheless, tannery effluents, if not properly treated, cause considerable damage to soil and water bodies thus, tanners are looking for cleaner and safer technologies. The industrial process most commonly employed by industry today, albeit its complexity is very flexible and adaptable to the raw materials and the characteristics of the final products wanted. A simplified scheme is reported showing the main steps involved for the transformation of hides into final leather goods [13] (Scheme 2).

In the first steps of the process or beamhouse operations (from soaking to bathing) the animal skins are treated in order to obtain collagen derma devoid salt, dirt, blood, hair, etc.

In the case of chrome salts a pickling stage (acidification) is required to prepare the skins for tanning by treatment with a mixture of strong/week acids (formic and sulphuric acid are the most used) in the presence of high concentrations of sodium chloride.
With the tanning process the skin is chemically stabilized and converted into a thermally and chemically stable material. Many different tanning agents have been tested both of natural and synthetic origin. The four main processes employed today by the leather industry are:

- Metal tanning, prevalently chrome salts

- Aldehydes

- Synthetic Tannins or Syntans

- Natural Tannins

All alternatives to chrome are limited in versatility and have higher processing costs; for example natural tannins are almost exclusively used for sole making and more than $25-30 \%$ by weight of tanning agent is required.

Very few examples are known today of efficient tanning, retanning agents obtained from leather waste.

At present over $85 \mathrm{w} \%$ of the world leather production is chrome tanned and only $20-25 \mathrm{w} \%$ of raw bovine hides processed is transformed in final leather goods. The leather industry produces waste equivalent to more than $50 \%$ in weight of starting raw material, in addition to sludge resulting from the purification of effluents.

The overall European tanneries are estimated to generate 400,000 ton of organic sludge per year. Approximately $50 \%$ of this waste is used to produce fertilizers [8], however a considerable part is not reused with loss of a valuable source of protein. It is estimated that at least $25 \%$ of waste currently ends up

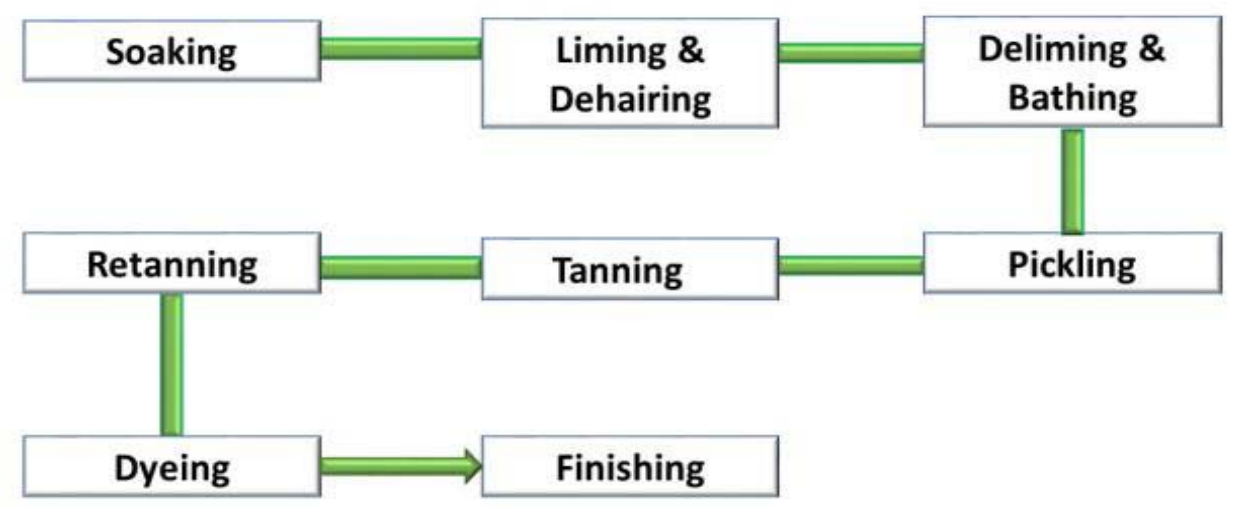

Scheme 2 Simplified scheme of the tanning process. 
in landfill.

This application would be particularly envisaged by the industry as it would reduce its waste disposal and transform it in a primary resource to reintroduce into the production cycle.

A preliminary research activity, has allowed selecting a class of different bio-mass feedstock to be used for the production of Biopol. Life Cycle Analyses of the new Biopol will be assessed and compared to conventional products.

HC collagen is transformed into an intermediate specie form which Biopol A, B, and C (Biopol A, Biopol B, Biopol C) are obtained according to Scheme 1.

The synthesis of the intermediate is carried out by reacting the water soluble $\mathrm{HC}$ protein and a condensing agent, in the presence of a polyol (see experimental section). This process is carried out in order to increase the number of carbonyl groups presented on the polymer which are responsible for the affinity of Biopols, with the collagen matrix and make this intermediate a good candidate also as filling and fat-liquoring agent.

Further, the intermediate is processed by polymerization reaction in the presence of acrylic acid. The resulting co-polymer has the capacity to react with chrome leather through coordination bonds, thanks to its carbonyl groups.

Alternatively, the intermediate is sulphited using sodium bisulfate, according to a standard industrial protocol for the production of Biopol C. This treatment increases solubility and penetration ability of the protein into the collagen compared to virgin oils.

HC and Biopol A, B and C are complex natural based organic compounds which may be characterized by different analytical and spectroscopic techniques. In this work we will combine the information achieved by different methods in order to collect important data such as molecular weight and chemical structure. The characterization of the proteins is necessary to provide an interpretation about the synthesis of the various tanning, retanning and fat liquoring agents. Moreover, the data collected are required to standardize the production and modification of the protein batches and provide a product as possible standardized from bath to batch. Spectroscopic magnetic resonance $1 \mathrm{H}$ NMR and FT-IR spectroscopy have been used so far to gather understanding preliminary information on the chemical composition of starting materials, intermediates and final bio-polymer, deriving from animal biomass.

A brief outline of the different technologies used for the characterization is given below. NMR can probe protein dynamics, kinetics, and thermodynamics all at atomic resolution. This technique is greatly helpful for the characterization of proteins smaller than $25 \mathrm{kDa}$ [14].

Infrared spectroscopy is one of the classical methods for structure determination of small molecules. This is due to its sensitivity to chemical composition and architecture of molecules which makes it a useful technique also for highly complex biological systems such as proteins [15].

Molecular weight of the samples has been estimate by using a SDS-PAGE (Sodium Dodecyl Sulphate-Poly Acrylamide Gel Electrophoresis). This technique is widely used to separate biological macromolecules, usually proteins or nucleic acids, but it can be helpful for our purposes since it can provide a first estimate of the molecular weights of $\mathrm{HC}$ and other processed samples.

${ }^{1} \mathrm{H}$ NMR in $\mathrm{D}_{2} \mathrm{O}$, FT-IR and SDS PAGE of HC are reported in Figs. 1 and 2 and are in accordance to literature data for enzyme $\mathrm{HC}$ of average molecular weight of ca 1,500-4,000 Da [12].

Preliminary characterization data on Biopol A highlight an increase in molecular weight and the presence of amide bonds formed from the reaction of the $\mathrm{NH}_{2}$ groups of the protein with the condensation agent. Ongoing studies will allow better characterizing the different Biopol. 


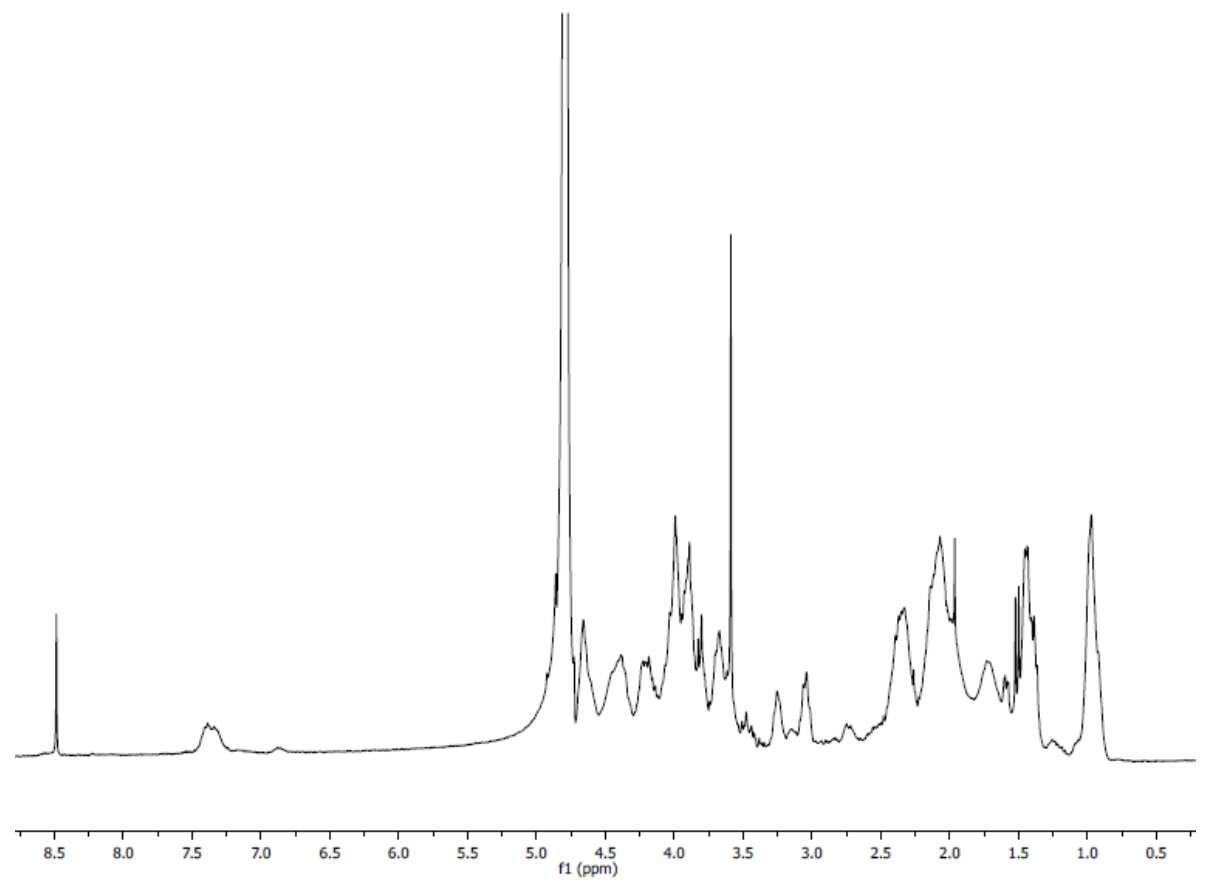

Fig. $1{ }^{1} \mathrm{H}$ NMR spectrum of $\mathrm{HC}\left(\mathrm{D}_{2} \mathrm{O}\right)$.

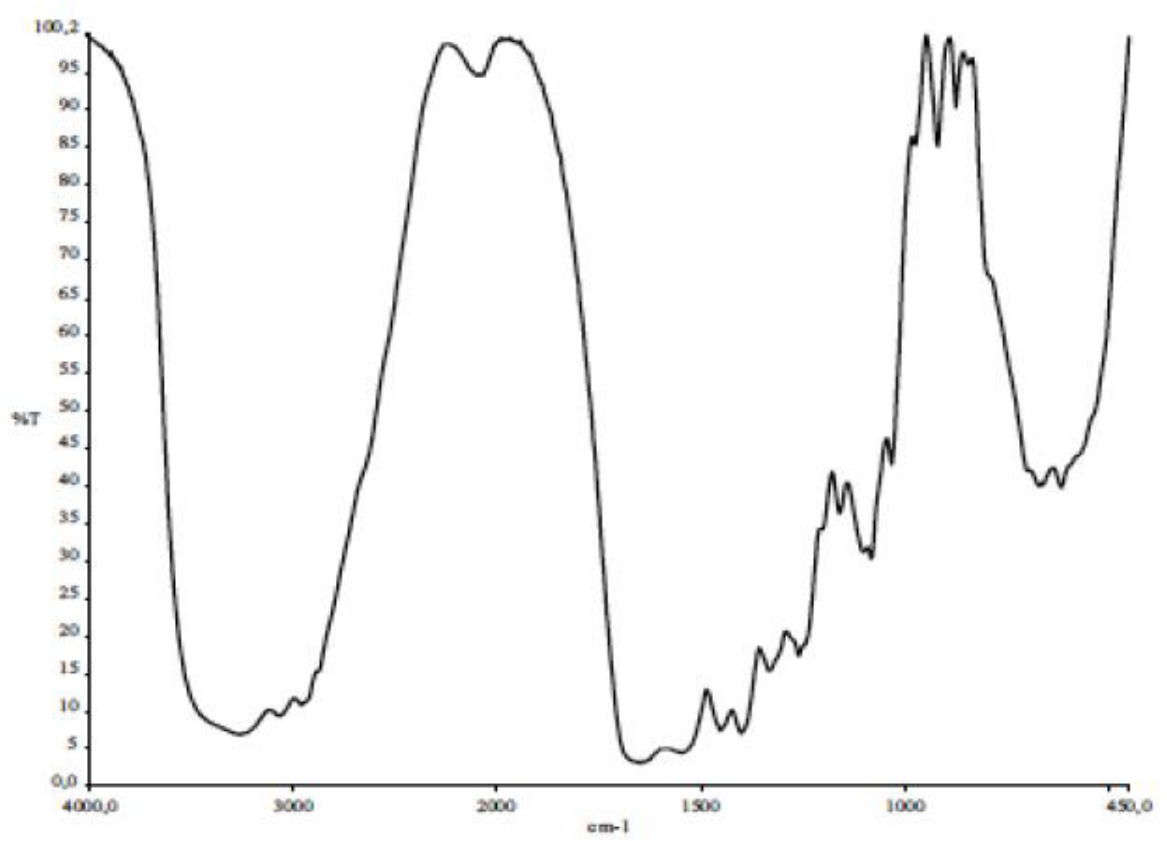

Fig. 2 FT-IR spectrum of $\mathrm{HC}(\mathrm{KBr})$.

The three Biopols synthesized have been preliminary tested as retanning agents starting from chrome tanned bovine leathers of a thickness of 1.1-1.2 mm as reported in Table 1. Amount of $10 \%$ of biopolymers, based on leather wet blue weight, has been used for application tests.
Biopol A led to very full crust, with a fine grain and pleasant feel.

Biopol B led to a very tight and firm crust.

Biopol C led to round and full leather with an excellent fiber lubrication effect.

It is evident from the data reported that the quality 
Table 1 Physical tests on leather crust.

\begin{tabular}{|c|c|c|c|c|c|}
\hline & EN ISO & A & $B$ & $C$ & Std \\
\hline $\begin{array}{l}\text { Tear load } \\
\left(\mathrm{N} / \mathrm{mm}^{2}\right)\end{array}$ & $3,377-1$ & 93 & 85 & 110 & 89 \\
\hline $\begin{array}{l}\text { Grain strenght } \\
(\mathrm{mm})\end{array}$ & 3,379 & 10 & 11 & 12 & 9 \\
\hline $\begin{array}{l}\text { Light fastness } \\
\text { blue scale }\end{array}$ & 105-B02 & 4 & $3 / 4$ & $3 / 4$ & $3 / 4$ \\
\hline Softness degree* & & $3+$ & 2 & $4+$ & 3 \\
\hline
\end{tabular}

A: Biopol A, B: Biopol B, C: Biopol C, Std: Standard treatment (5\%wt Acrylic Resin + 5\%wt Phenol Syntan), Leather thickness: 1.2 mm. * Values between 1-5.

of the finished leather obtained with Biopol A, B, C is in all cases comparable or superior to standard treatment.

\section{Conclusions}

A green and eco-friendly method for the synthesis of tanning agents based on biopolymers has been studied starting from leather waste. The new biopolymers are non hazardous chemicals and do not show any danger in manipulation and use in tannery process.

Several protocols involving polymerization, esterification, and sulphitation are being tested to produce chemicals able to replace the traditional re-tanning and fat-liquoring auxiliaries. Macromolecular characterization of the biopolymers gave important indication on the synthesis procedure strategy and practical application of the products.

Preliminary retanning tests with the three Biopols give very good results in all cases equivalent or even superior to conventional retanning protocols.

\section{Acknowledgments}

This study is supported and co-financed by LIFE PROGRAMME with LIFE15 ENV/IT/000654 code. Authors are grateful to Codyeco and Univesity Ca' Foscari personnel for supporting technical analysis. Ilsa Group is also gratefully acknowledged for supplying animal biomass.

\section{References}

[1] Black, M., Canova, M., Rydin, S., Scalet, B. M., Roudier,
S., and Delgado Sancho, L. 2013. "Best Available Techniques (BAT) Reference Document for the Tanning of Hides and Skins: Industrial Emissions Directive 2010/75/EU: (Integrated Pollution Prevention and Control).” Publications Office of the European Union. http://publications.jrc.ec.europa.eu/repository/handle/JRC 83005.

[2] Ranjithkumar, A., Durga, J., Ramesh, R., Rose, C., and Muralidharan, C. 2016. "Cleaner Processing: A Sulphide-Free Approach for Depilation of Skins.” Environental Science Pollution Research.

[3] Chaudhary, P., Chhokar, V., Kumar, A., and Beniwal, V. 2017. "Bioremediation of Tannery Wastewater." Advances in Environmental Biotechnology (April): 125-44.

[4] http://ec.europa.eu/environment/waste/.

[5] United Nations Industrial Development Organization. "Sustaining Employment Growth: The Role of Manufacturing and Structural Change." www.unido.org/fileadmin/user_media/Research_and_Stat istics/UNIDO_IDR_2013_main_report.pdf.

[6] Beghetto, V., Zancanaro, A., Scrivanti, A., Matteoli, U., and Pozza, G. 2013. "The Leather Industry: A Chemistry Insight Part I: An Overview of the Industrial Process.” Ed. Ca' Foscari. 1 (April): 13-22.

[7] Kanagaraj, J., Senthilvelan, T., Panda, R. C, and Kavitha, S. 2015. "Eco-Friendly Waste Management Strategies for Greener Environment towards Sustainable Development in Leather Industry: A Comprehensive Review.” Journal of Cleaner Production 89 (February): 1-17.

[8] Lima, D. Q., Oliveira, L. C. A., Bastos, A. R. R., Carvalho, G. S., Marques J. G. S. M., Carvalho, J. G., and Souza, G. A. 2010. "Leather Industry Solid Waste as Nitrogen Source for Growth of Common Bean Plants." Applied and Environmental Soil Science 2010 (July): 7.

[9] http://eippcb.jrc.ec.europa.eu/reference/.

[10] Sheldon, R. A. 2016. "Green Chemistry and Resource Efficiency: Towards a Green Economy.” Green 
Chemistry 18 (November): 3180-3.

[11] ec.europa.eu/eurostat/documents/.../e47b231c-c411-4d4e8cd6-e0257be4f2e6?.

[12] Castiello, D., Chiellini, E., Cinelli, P., D’Antone, S., Puccini, M., Salvadori, M., and Seggiani, M. 2010. "Polyethylene-Collagen Hydrolizate Thermoplastic Blends: Thermal and Mechanical Properties.” Journal of Applied Polymer Science 114 (August): 3827-34.
[13] Covington, A. D. 2011. 2009 Tanning Chemistry. The Science of Leather. Cambridge: RSC Publishing.

[14] Frueh, D. P., Goodrich, A. C., Mishra, S. H., and Nichols, R. S. 2013. "NMR Methods for Structural Studies of Large Monomeric and Multimeric Proteins.” Current Opinion in Sctructural Biology 23 (October): 734-9.

[15] Barth, A. 2007. "Infrared Spectroscopy of Proteins." Biochimica et Biophysica Acta. (September): 1073-101. 